\title{
Growing-season and degree-day scenario in Norway for 2021-2050
}

\author{
Torill Engen Skaugen*, Ole Einar Tveito
}

Norwegian Meteorological Institute, Climatology Division, PO Box 43 Blindern, 0313 Oslo, Norway

\begin{abstract}
Temperature is projected to increase in Norway over the next 50 yr. Even though it is supposed to increase most during winter, the expected temperature increase in the summer as well as in spring and autumn will lead to a longer thermal growing season all over the country. The growing degree-day sum within the growing season is projected to increase all over the country. The largest increase is projected to occur along the western coast of Norway, while the smallest change is projected to occur in the high mountainous part of the country. The study is based on empirically downscaled temperature data from ECHAM4/OPYC3 with the GSDIO integration. The results are obtained with a spatially distributed model for which downscaled temperature data are used as input.
\end{abstract}

KEY WORDS: Growing season - Growing degree-day sum - Climate scenarios · Air temperature Resale or republication not permitted without written consent of the publisher

\section{INTRODUCTION}

Climate in Norway shows large variability, both between seasons and between different regions. The winters are generally mild along the coast due to the vicinity of ocean waters. In inland regions, the winter season is cold, and the ground is usually frozen and covered with snow. The summer is warm and dry in continental regions, while the climate along the coastline is humid and mild in this season. The variation between the seasons is smallest along the coast, and largest inland. At some inland locations, differences between winter-minimum and summer-maximum temperature may exceed $70^{\circ} \mathrm{C}$.

Plant growth is in general strongly related to air temperature, and it is especially vulnerable during spring (Menzel 2002, Sparks \& Menzel 2002). Air temperature is found to be a limiting factor for growth potential; thus the growing season (GS) is rather short at high latitudes. Different species respond differently to air temperature: some are sensitive to lower temperatures, while others are more resistant to cold climate.

Since the early 1960s, the length of the vegetation period has increased through advanced onset of the beginning of the growing season (BGS) in mid- latitudes (Menzel \& Fabian 1999). The BGS shows distinct year-to-year variability, but since 1989 it has clearly advanced (Chmielewski \& Rötzer 2002). An increased GS may also lead to a change in insect activity and distribution. However, other climate parameters, such as change in precipitation and humidity, are also of major importance with regard to insect activity (Patterson et al. 1999).

Different possible definitions of the GS are available (Brinkman 1979). The number of days with daily mean air temperatures (at $2 \mathrm{~m}$ above ground level) above a given threshold temperature is often used. Plant growth is insignificant when the daily mean temperature is below $5^{\circ} \mathrm{C}$. The $5^{\circ} \mathrm{C}$ threshold has become the standard definition for the base temperature when estimating the GS and growing degree-day sum (GDD). The GDD is the effective temperature sum indicating the intensity of the GS (Carter 1998).

Since air temperature varies with altitude, distance from the coast and latitude, the temperature-based definition of the GS reflects that one type of crop can start to grow earlier and last longer at one geographical site than another.

There has been large variability in annual temperature during the last 100 to $150 \mathrm{yr}$ in Norway, directly 
affecting the GS. Within the 2 time periods from 1876 to the 1930s and from the 1960s and/or 1970s to 1997 , there has been a significant temperature increase all over the country. There was a significant temperature decrease in Norway from the 1930s up to 1970 and/or 1970 s in almost all regions. In total, the annual air temperature has increased since 1876 until present by between 0.4 and $1.2^{\circ} \mathrm{C}$ in different regions of Norway (Hanssen-Bauer \& Nordli 1998). Førland et al. (2000) has shown that the air temperature in Norway increased during the last 2 decades, 1980-1999, compared to the recent standard normal period, 1961-1990 (referred to as the reference period below).

Different coupled atmospheric-ocean global circulation models (AOGCMs) have estimated scenarios with rather large differences for future global climate, especially at high latitudes (Cubasch et al. 2001). However, all models indicate a warming in Norway over the next 50 to 100 yr (Räisänen 2001). Downscaled results of one AOGCM, both empirically and dynamically, show that annual warming rates are projected to be between 0.2 and $0.5^{\circ} \mathrm{C}$ decade $^{-1}$ up to 2050 on the Norwegian mainland. On the west coast of southern Norway, the results show similar change for all seasons $\left(0.2\right.$ to $0.3^{\circ} \mathrm{C}$ decade $\left.^{-1}\right)$. Further north and in inland valleys, considerably larger warming rates in winter $\left(0.5^{\circ} \mathrm{C}\right.$ decade $\left.^{-1}\right)$ than in summer have been estimated (Bjørge et al. 2000, Hanssen-Bauer et al. 2000, 2003).

Høgda et al. (2001) found that the GS increased between 1982 and 1998, especially along the southern coast of Norway (28 to 42 d) and southern Sweden ( $>42 \mathrm{~d}$ ). They used the normalized difference vegetation index (NDVI) derived from satellite images (NOAAAVHRR) to define the GS. The GS was set to the period of the year when the value of the NDVI was $>\sim 0.2$.

Carter (1998) studied the future change in the GS and GDD, based on the same thermal definition as presented here, at 9 locations in Fennoscandia. One of these sites was located in southern Norway. Carter used both historical observations and climate scenarios, which showed an extension of the GS in southern Norway of 45 d by 2050. That study was based on 3 scenarios from the Finnish Research Programme on Climate Change (SILMU) (Carter et al. 1996).

In order to evaluate the future climate-change impact on the mean GS and GDD in Norway, a detailed study applying a spatially distributed model was carried out. Temperature data derived from the Max Planck Institute's ECHAM4/OPYC3 AOGCM (Roeckner et al. 1999) was utilized by empirical downscaling (Hanssen-Bauer et al. 2000, 2003) for the $30 \mathrm{yr}$ period 2020-2049 (referred to as the scenario period). The downscaled temperatures are used as input to a spatial model, including GS and GDD algorithms, comparing present and future conditions.

\section{TEMPERATURE DATA}

One temperature scenario based on the ECHAM4/ OPYC3 AOGCM with the GSDIO integration is used. The model describes the global climate from 1860 up to 2050 (Roeckner et al. 1999). This is a transient integration, including greenhouse gases, tropospheric ozone, and direct as well as indirect sulphur aerosol forcing. In this integration, the concentration of greenhouse gases has been specified according to the IPCC IS92a scenario, with an increase in $\mathrm{CO}_{2}$ giving a near doubling in $100 \mathrm{yr}$ (Cubasch et al. 2001). The model gives a realistic description of the present climate in Norway and was therefore chosen as a basis for the downscaling of temperature and precipitation in Norway (Allen et al. 2000).

Two downscaling techniques from AOGCMs, dynamical and empirical (or statistical), have been applied in Norway to establish projected climate scenarios for the future. Dynamical downscaling utilizes results from the AOGCM as input in a regional weather forecast model with finer resolution, and it provides daily values (Bjørge et al. 2000). Empirical downscaling techniques involve the use of empirical links between observed large-scale atmospheric fields, such as air pressure or sea-surface temperature, and local climate elements, such as temperature or precipitation. These relations are used to estimate monthly values of temperature and precipitation values locally (Hanssen-Bauer et al. 2000, 2003).

In this study empirically downscaled temperature data were utilized. Even though the time resolution is on a monthly basis, the at-site representation of empirical downscaled temperature data is better represented compared to dynamically downscaled data (Hanssen-Bauer et al. 2003). The objective of this study was to evaluate mean changes in the future GS and GDD compared to present. An approach deriving mean daily temperature values from mean monthly temperature values was applied. The method ensures a smooth annual temperature curve, avoiding the problem of daily fluctuations around $5^{\circ} \mathrm{C}$.

Empirically downscaled temperature values were obtained at 46 locations in Norway (Fig. 1).

\section{METHODS}

\subsection{Estimation of daily mean temperature from monthly mean temperature}

To estimate the GS and the GDD, daily mean temperatures must be available. For historical time periods, such values can be obtained using the observed daily values. The empirically downscaled temperature 


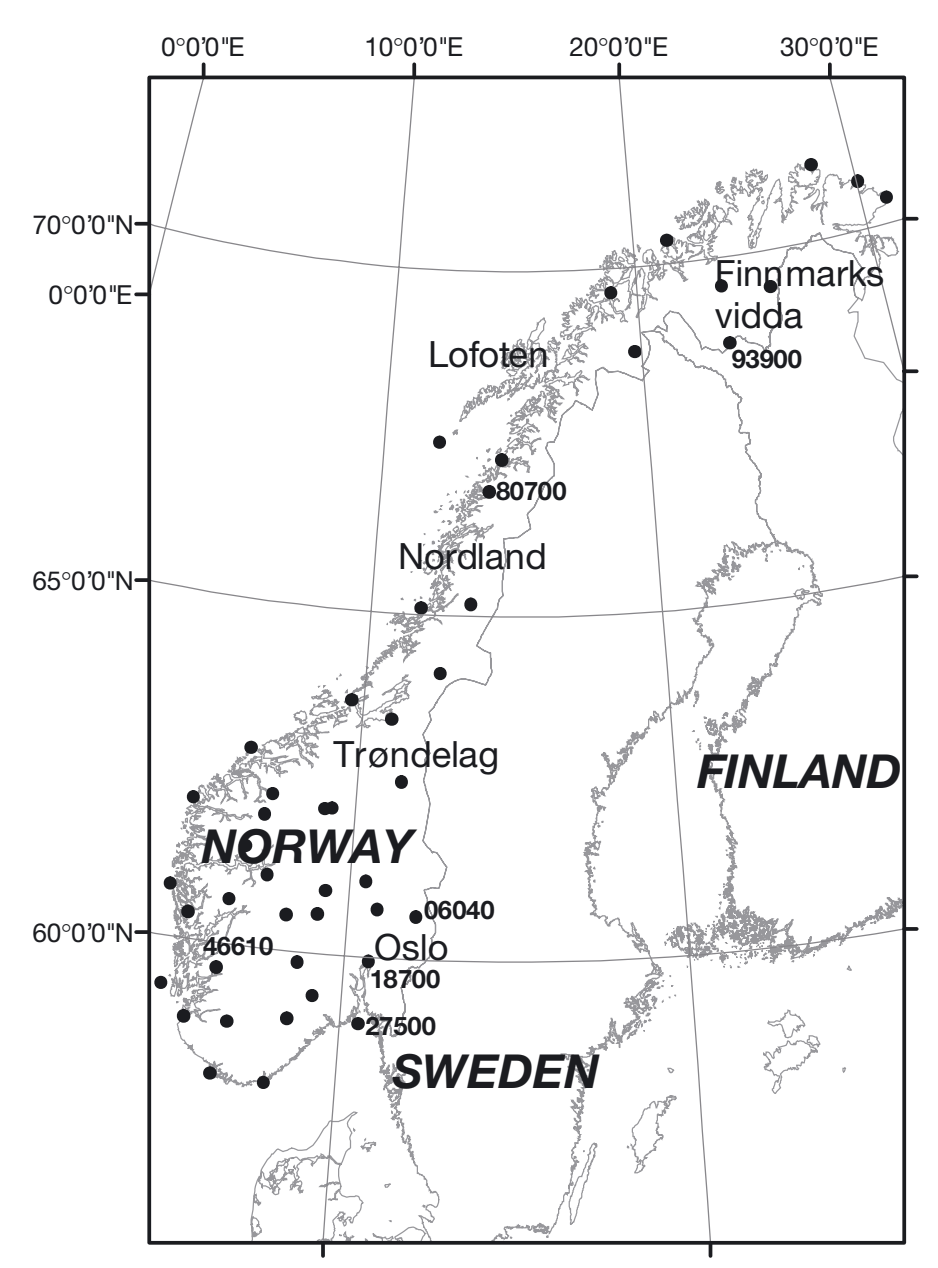

Fig. 1. Weather stations in Norway used for the scenario period 2021-2050

scenario of the future climate contains only mean monthly temperature estimates. As described by Carter (1998), the beginning and end of the GS may be ambiguous. This is because the daily mean temperature may rise and drop above and below the threshold temperature a few times in spring. To avoid the influence of this day-to-day variability of daily values, Groisman et al. (2003) defined the start and end of the GS by the dates of steady (at least $5 \mathrm{~d}$ long) transition of mean daily temperatures across a threshold temperature. For Finland, Venäläinen \& Nordlund (1988) specified the start of the GS when daily mean temperatures exceed $5^{\circ} \mathrm{C}$ for at least 5 consecutive days in the spring, and the end when the $10 \mathrm{~d}$ running mean falls below $5^{\circ} \mathrm{C}$. In the present study, the estimates of GS were based on smoothed daily mean temperatures deduced from average monthly temperatures. Applying this approach to both historical and scenario temperatures ensures consistent values for both periods analyzed.
Daily mean temperatures are interpolated from the mean monthly temperatures by a spline curve (Press et al. 1992). The curve is fitted through the 12 monthly mean temperatures. An example from Oslo-Blindern is shown in Fig. 2. A constraint is added to the spline equation to ensure that the deviation between the gridded mean monthly temperature and the mean monthly temperature based on the estimated daily temperature values does not exceed $0.001^{\circ} \mathrm{C}$, defined as the tolerance criterion. The amplitude of the spline curve is adjusted by shifting the positions of the monthly mean (default in the middle of the month). This is done iteratively until the tolerance criterion is fulfilled. The technique provides a simple, fast and robust method which can be applied everywhere when only mean monthly temperatures are available. It is highly suitable for the analysis of large spatially distributed (gridded) datasets with limited computational effort. As shown in Fig. 2, the method reproduces the daily mean temperatures satisfactorily. An evaluation of the spline technique for establishing mean daily temperatures by comparing them to observed daily values is shown in Appendix A. It is shown that there are only marginal differences between GS estimated from observed and estimated mean daily temperatures.

\subsection{Spatial interpolation of temperature}

Mean monthly temperature maps for Fennoscandia were established for the reference period by Tveito et al. (2000). The maps were derived from temperature observations at about 1150 stations all over Fennoscandia, of which 421 are situated in Norway, by applying a residual kriging approach (Davis 1973). The grid resolution of the maps is $1 \times 1 \mathrm{~km}^{2}$.

Spatial interpolation of absolute temperatures is concerned with difficulties due to a sparse station network and large variability over short distances. Spatial interpolation methods are usually based on assumptions of second-order stationarity and isotropy. These assumptions are not fulfilled when considering absolute temperatures. The temperatures must therefore be transformed in order to obtain 'fields' that fulfil the assumptions. By normalizing the mean monthly temperature values for the scenario period, the assumptions are almost fulfilled. The normal value is subtracted from the mean temperature value for the scenario period. In the resulting anomalies, spatial climate trends are removed. By performing spatial interpolation on the anomalies, more robust estimates are obtained compared with interpolation of absolute temperature values. The interpolation procedure TOPOGRID is used to interpolate the anomalies. It is 


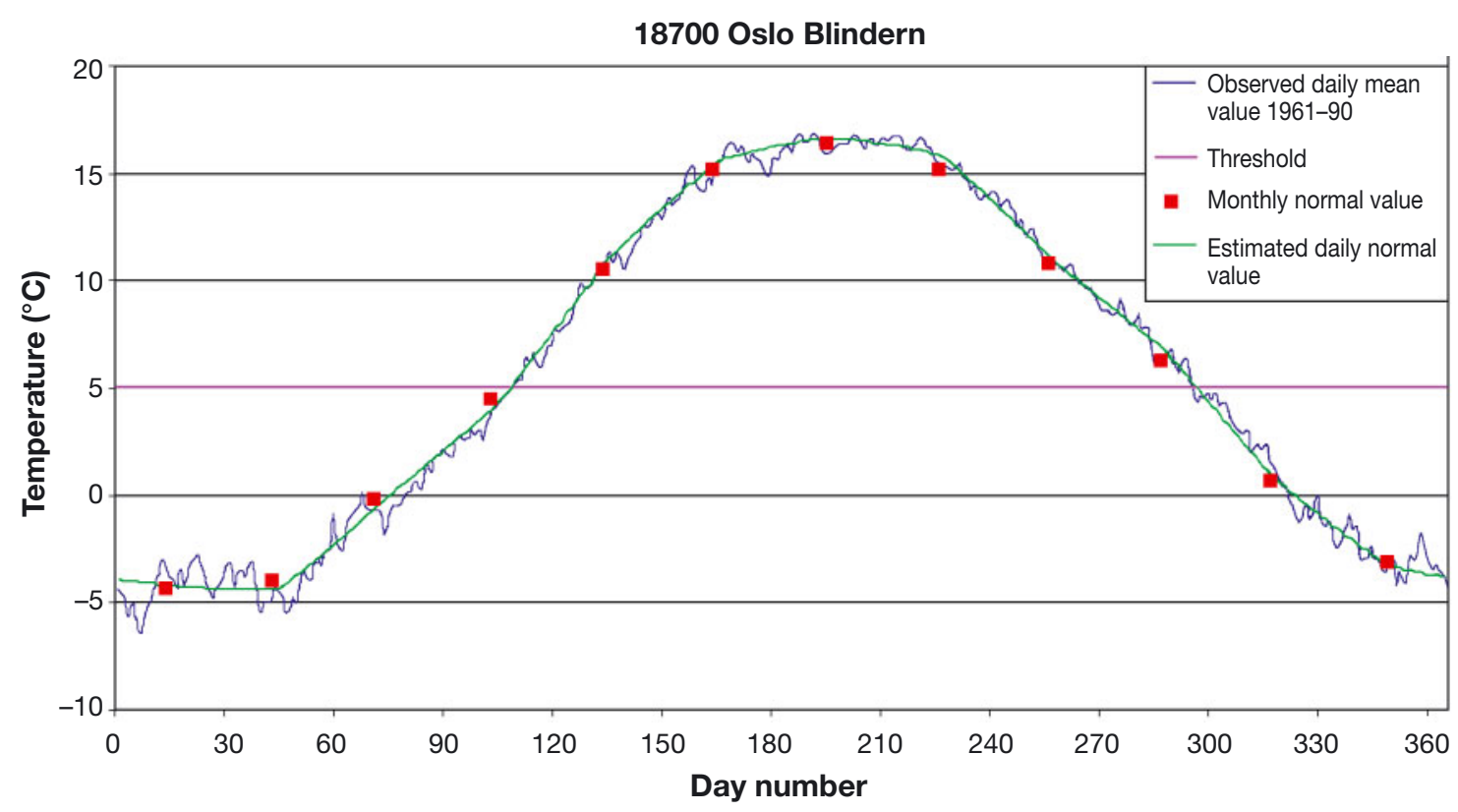

Fig. 2. Observed daily mean temperature, estimated daily mean temperature and mean monthly temperature at Stn 18700 Oslo-Blindern during 1961-1990 (from Tveito et al. 2001)

essentially a discretized thin-plate spline technique (Wahba 1990). An evaluation of the spatial interpolation method of temperature anomalies is presented in Appendix B.

Maps of mean monthly temperature for the scenario period were obtained by adding the anomaly maps to the temperature maps for the reference period. The resolution of the maps is $1 \times 1 \mathrm{~km}^{2}$.

Daily mean temperatures for both the reference period and the scenario period were found by applying the spline technique for each grid cell in the derived maps.

\subsection{Calculating growing season and growing degree-days}

The GS is defined as the period of the year when the daily mean temperature is above $5^{\circ} \mathrm{C}$ (Carter 1998). A smoothed curve of daily mean temperatures is established for each grid cell in the temperature map based on the 12 mean monthly values. The BGS, the end of the growing season (EGS) and the length of the GS can thus be calculated for each cell in the grid.

The GDD are defined as the accumulated degree sum above a defined reference temperature (Carter 1998):

$$
\mathrm{GDD}=\sum_{i=1}^{365}\left(T_{i}-\hat{T}\right), T_{i} \geq \hat{T}
$$

where $T_{i}$ is the daily reference temperature for Day $i$ and $\hat{T}$ is the threshold temperature $\left(5^{\circ} \mathrm{C}\right)$.

\section{RESULTS AND DISCUSSION}

\subsection{Growing season}

The length of the GS varied from less than $50 \mathrm{~d}$ in the high mountainous areas of southern Norway to more than $200 \mathrm{~d}$ in a narrow zone along the southwestern coast of the country in the reference period (Fig. 3a). The length of the GS shows patterns similar to topography (Fig. 4).

The largest change in GS in the scenario period compared to the reference period was projected to occur in the western part of the country, in Nordland and in the northernmost part of Norway (>40 d) (Fig. 3b). In the Oslo and Trondheim area, and the inner part of Finnmarksvidda, the change was projected to be smallest $(<20 \mathrm{~d})$.

Fig. 5 shows an example of the mean daily temperature estimates for the periods studied at Stn 06040 (Flisa) (see Fig. 1). The projected increase in length of the GS is advanced by almost the same number of days in the spring as it is delayed in the autumn. Fig. 5 also shows, as stated by Hanssen-Bauer et al. (2000, 2003), that the temperature increase is projected to be largest during winter.

The BGS for the reference period began between the middle of April (coastal area in southern parts of Norway) and the end of May at altitudes up to ca. $900 \mathrm{~m}$ above sea level (masl). In the high mountainous areas of Norway, with altitudes above 900 masl, and in Finnmark, the GS started in June and even as late as in the 


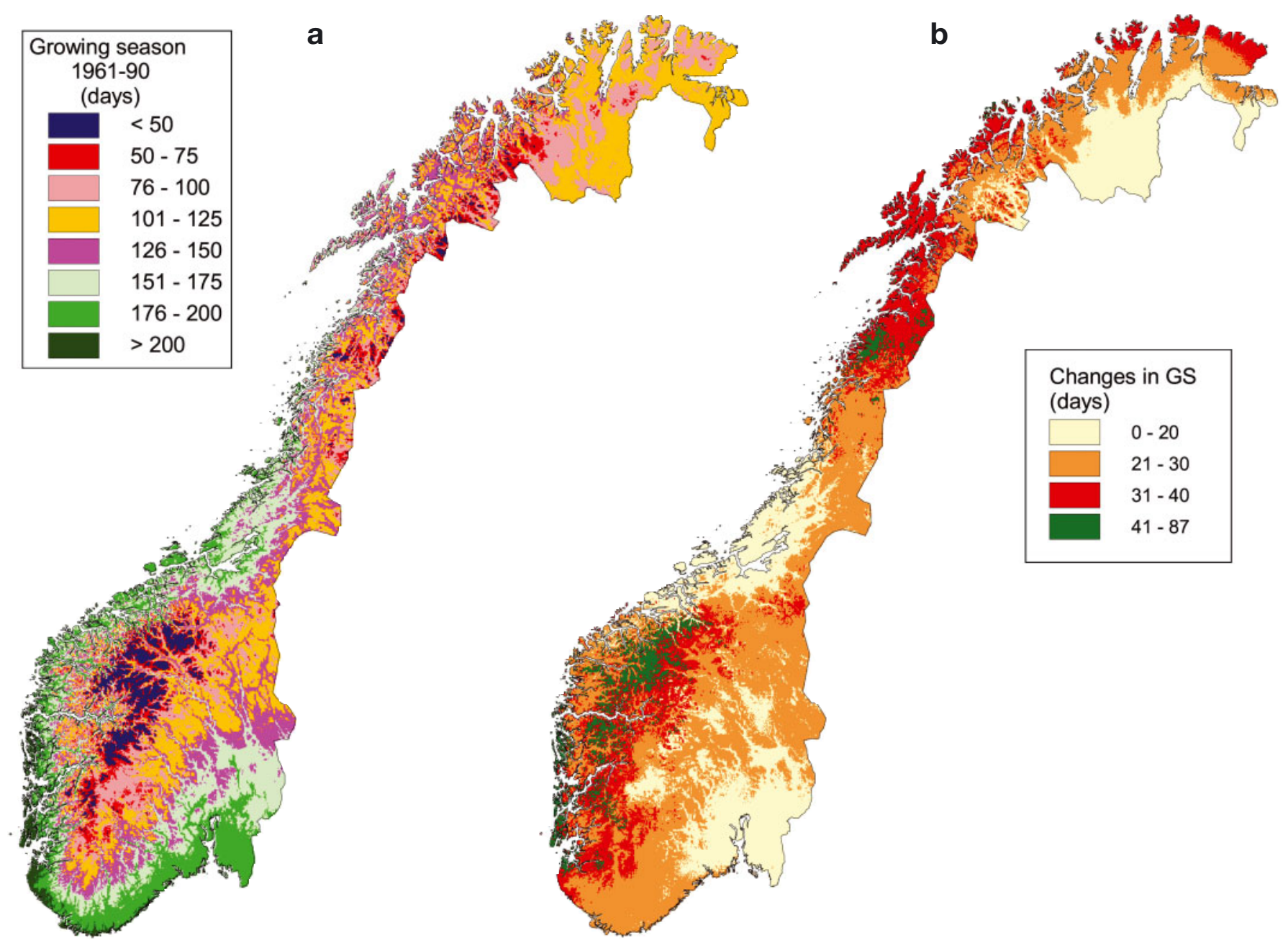

Fig. 3. (a) Growing season (GS) in Norway, mean value for the reference period. (b) Changes in GS for the scenario period 2021-2050 compared with the reference period

middle of August. This very late start of the GS is in regions where there are only a few days with mean daily temperatures above $5^{\circ} \mathrm{C}$ (Fig. 6a).

The projected change in the BGS in Norway in the scenario period compared with the reference period (Fig. 6b) shows the same pattern as for the projected change in the length of the GS. The cumulative frequency curves of the BGS and EGS (Fig. 7) show that for $50 \%$ of the total area of Norway in the reference period the GS started before Day 145 (25 May). For the scenario period, this day was 11 d earlier, at Day 134 (14 May). For the EGS, $50 \%$ of the total area was in the GS until Day 263 (20 September) in the reference period. For the scenario period, this day was 16 d later, at Day 279 (6 October). Consequently, the GS is projected to become almost $4 \mathrm{wk}$ ( $26 \mathrm{~d}$ ) longer for $50 \%$ of the country.

The length of the GS has already been mapped based on historical phenological observations of average date of leaf unfolding for 4 different plant species in Europe for 1961-1998 (Rötzer \& Chmielewski 2001). The plant species were observed at the International Phenological Gardens (IPGs) in Europe. The IPGs in Europe have genetically identical clones of trees and shrubs (Menzel \& Fabian 1999). However, only 3 IPGs are located in Norway. The map of Rötzer \& Chmielewski (2001) shows that the GS is between $120 \mathrm{~d}$ in the high mountainous areas and about $180 \mathrm{~d}$ along the coast of Norway. The geographical pattern is similar to the present results; however, the range is somewhat smaller $(<50 \mathrm{~d}$ in the mountainous areas to $>200 \mathrm{~d}$ on the western coast; Fig. 3a).

Rötzer \& Chmielewski (2001) have shown that regions such as the southern UK, The Netherlands and northern Germany had an average GS from ca. 200 to $210 \mathrm{~d}$ in 1961-1998. This means that the average length of the GS along the southern coast of Norway in 2021-2050 will be as it is today in those European countries. 


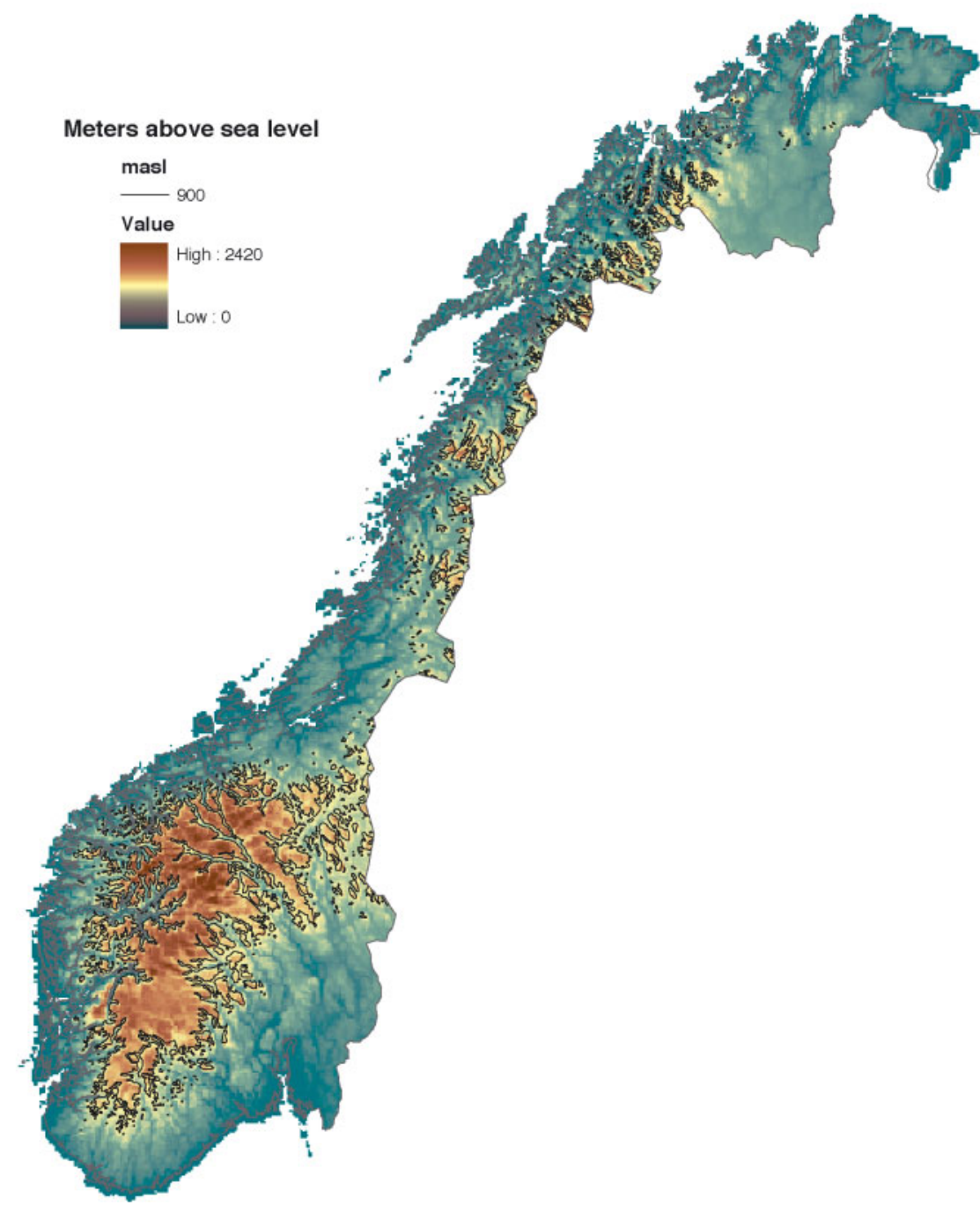

Fig. 4. Elevation map of Norway showing the $900 \mathrm{~m}$ above sea level (masl) contour line

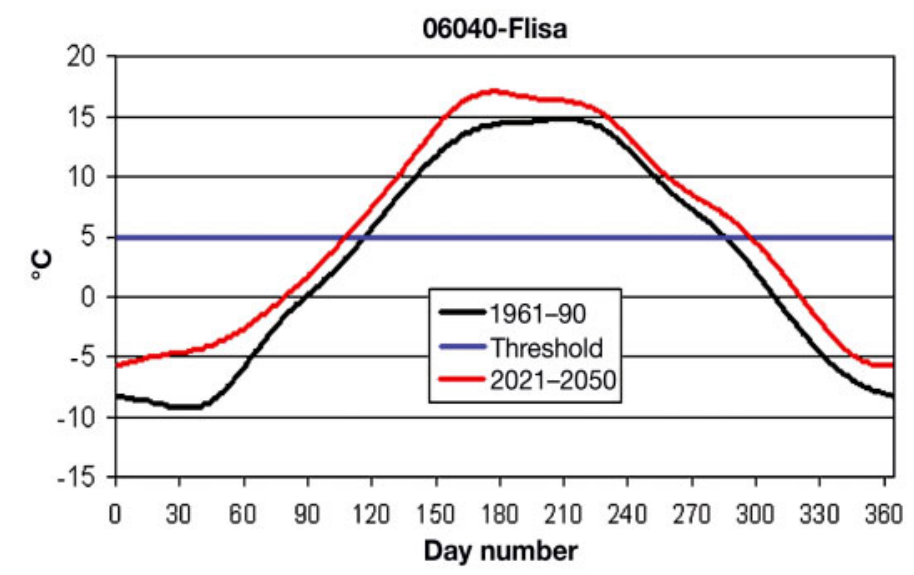

Fig. 5. Estimated daily mean temperature at Stn 06040 (Flisa) for the reference and scenario periods. Threshold temperature is indicated
Carter (1998) showed that, with the SILMU scenarios, the GS at Stn 27500 (Ferder Fyr), on the southeastern coast of Norway (Fig. 1), would increase by $45 \mathrm{~d}$ by 2050 . This is a $\sim 100 \%$ larger increase than indicated by the study presented here. The results presented are based on mean monthly temperature values in the reference period compared with those in the scenario period. Thus, the estimate is for $30 \mathrm{yr}$ mean values in the future, not the actual situation in 2050. Carter's estimate is based on 3 global climate models, different from the one used in this study, for 2050 compared to the reference period (Carter et al. 1996). Larger variations can be expected by comparing different years. Stn 27500 (Ferder Fyr) is a coastal station. The result obtained by Carter (1998) is thus not directly comparable to the present study.

\subsection{Growing degree-days}

The GDD in the reference period (1961-1990) in Norway varied from less than 200 to more than $1200^{\circ} \mathrm{C}$ (Fig. 8a). A belt from the Swedish border to the Trondheimfjord area, and a narrow belt further along the coast from here to Lofoten had the largest GDD, more than $700^{\circ} \mathrm{C}$. Northern Norway and interior regions of the country had GDD estimates between 200 and $700^{\circ} \mathrm{C}$. In the mountainous areas in southern and northern Norway, the GDD estimate was less than $200^{\circ} \mathrm{C}$.

The projected change in GDD in the scenario period compared with the reference period in Norway is presented in Fig. 8b. The projected change is estimated to be between 300 and $480^{\circ} \mathrm{C}$ in western Norway and along parts of the northern coast. In parts of northern Norway and high mountainous areas, the change will be less than $200^{\circ} \mathrm{C}$. The eastern part of southern Norway, the Trondheim area and coastal and inner parts of northern Norway, the change is projected to be between 200 and $300^{\circ} \mathrm{C}$.

The frequency curve of the GDD for the 2 periods studied (Fig. 9) shows that the intensity of the GS will increase throughout the whole country. Of the total area of Norway $50 \%$ has a mean intensity of the GS in the reference period up to $\sim 400^{\circ} \mathrm{C}$. In the scenario period the same portion of the country had an increase in intensity of the GDD up to $\sim 650^{\circ} \mathrm{C}$. 


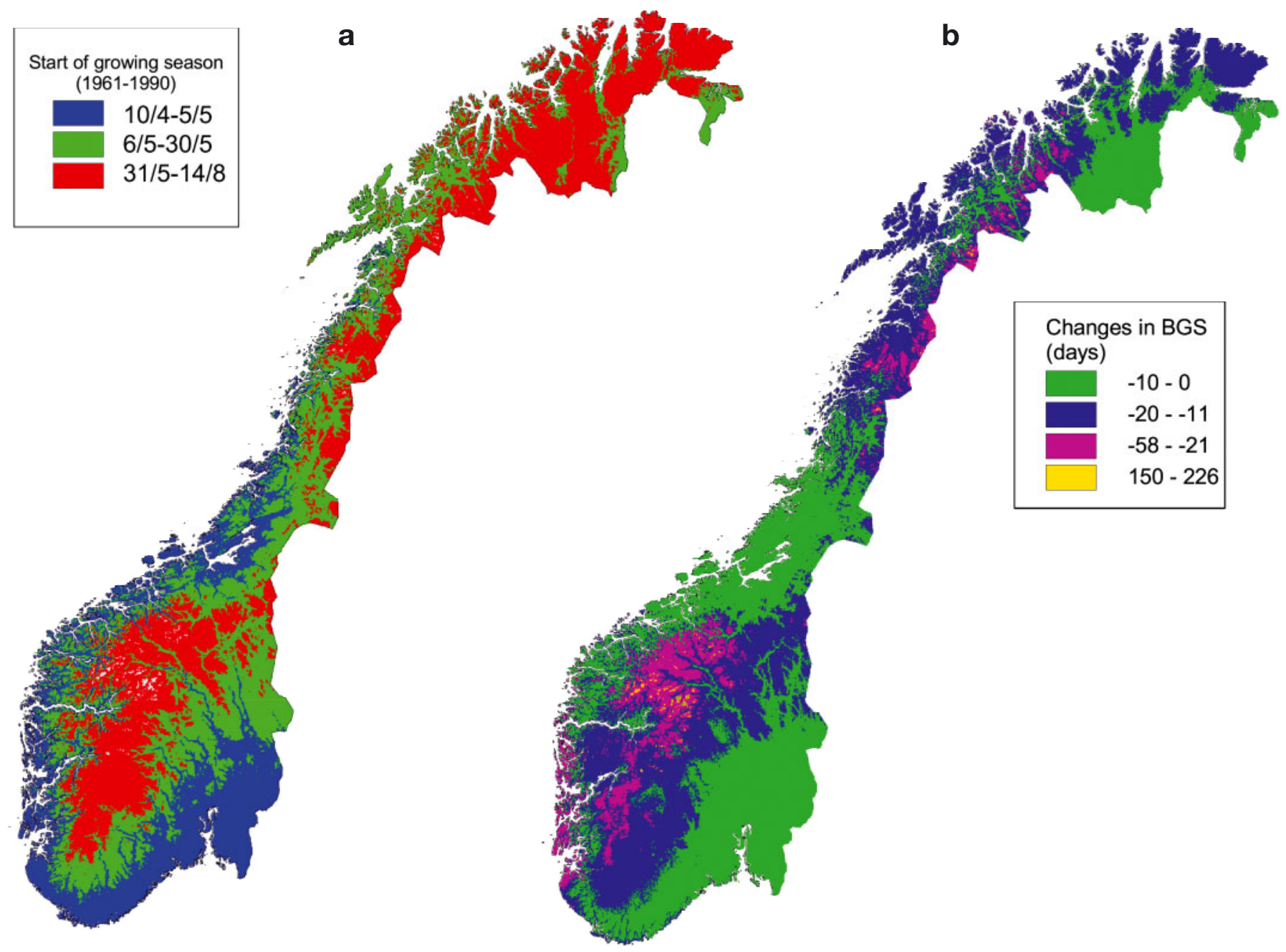

Fig. 6. (a) Beginning of growing season (BGS) in Norway, mean value for the reference period. (b) Change in the BGS for the scenario period compared with the reference period

\section{SUMMARY AND CONCLUSIONS}

Temperature scenarios for Norway show that the largest temperature increase in 2021-2050 is projected to occur in the winter season. However, a significant temperature increase during the spring, summer and autumn seasons is projected as well. This will lead to a longer GS all over the country compared with the reference period. The strongest increase in the GS is found in the western parts of the country, in Nordland and at the northernmost coastal zone in Finnmark. The latter is probably due to the maritime influence at the stations used in this analysis, which in this area are mainly lighthouse stations.

The GDD will increase all over the country, and the largest increase will occur along the coast. As a good indicator of energy available for biological growth during the GS, an increase in the GDD may lead to heavier growth of the crops already present. A marked

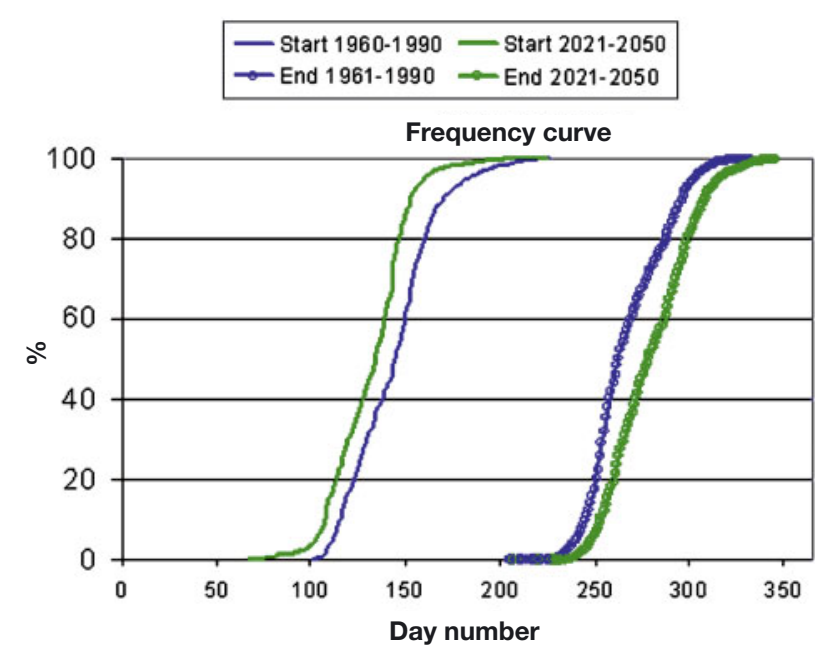

Fig. 7. Cumulative frequency curves of the spatial distribution for the beginning and end of the GS for the reference and scenario periods 


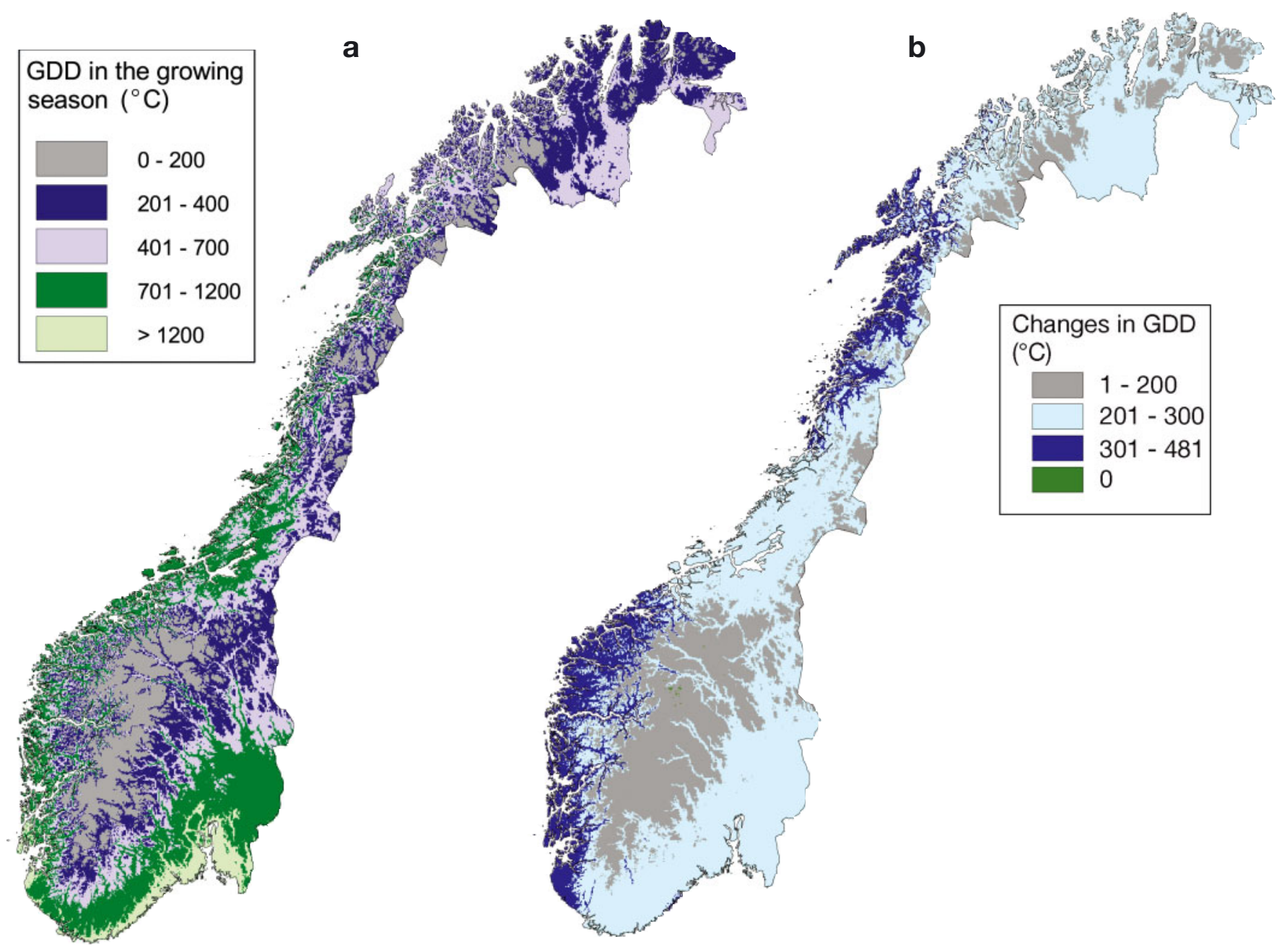

Fig. 8. (a) Growing degree-days (GDD) in Norway, mean value for the reference period. (b) Change in the GDD for the scenario period compared with the reference period

increase in GS and GDD, as the scenario indicates, may also result in the introduction of new species-plants and, e.g., insects. Problems may therefore occur, such as damage caused by increased numbers of insects as well as a higher risk of plant disease. However, this study alone cannot be used to make such conclusions, since other important aspects, e.g. moisture conditions and radiation, have not been considered.

When studying the effects of climatechange scenarios, one must be aware of the encumbrance of uncertainties in the results. The temperature scenarios used are based on empirical downscaling from only 1 AOGCM at only 46 stations covering Norway. These stations may not represent all the spatial variability in the GS and the GDD. Both the spatial interpolation method and the

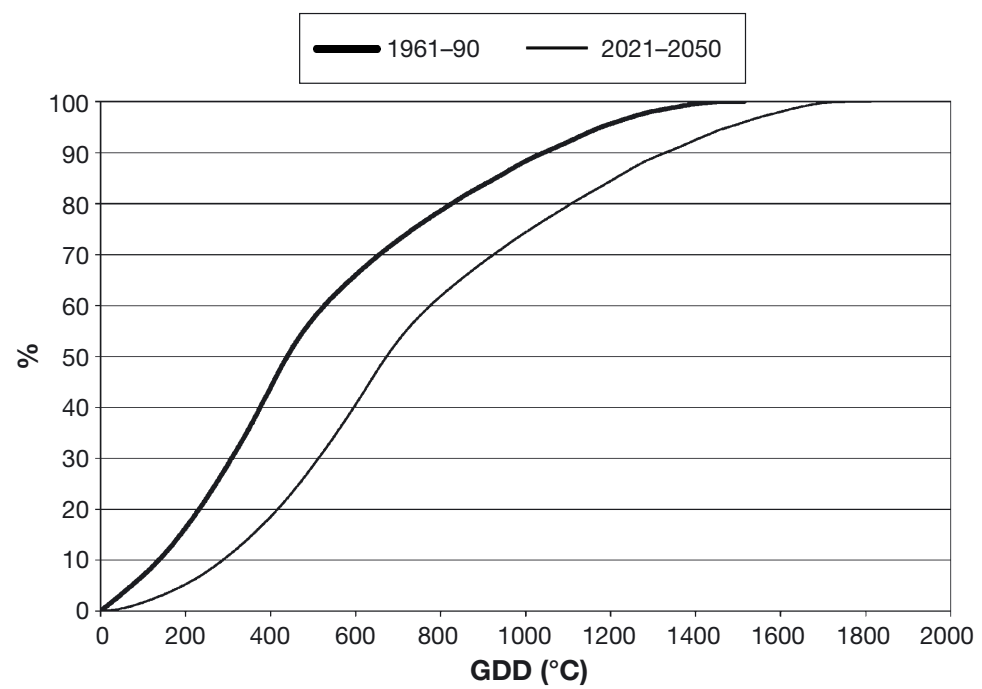

Fig. 9. Cumulative frequency curves of the spatial distribution of GDD for the reference and scenario periods 
downscaling method have uncertainties. The combination of all these points makes the uncertainty difficult to quantify.

Acknowledgements. We would like to thank our colleagues E. J. Førland and I. Hanssen-Bauer for valuable discussions and suggestions, and S. L. Lystad for the mean daily temperature algorithm. The critical and useful comments from 2 anonymous reviewers are also acknowledged. The study was done under the Norwegian Regional Climate Development (RegClim) Program supported by the Norwegian Research Council of Norway (Contract NCR-No. 120656/720) and the Norwegian Meteorological Institute (met.no).

\section{LITERATURE CITED}

Allen MR, Skott PA, Mitchell JFB, Schur R, Delworth TL (2000) Quantifying the uncertainty in forecasts of anthropogenic climate change, Nature 407:617-620

Bjørge D, Haugen JE, Nordeng TE (2000) Future climate in Norway. DNMI Research Report No. 103, Norwegian Meteorological Institute, Oslo

Brinkmann WAR (1979) Growing season length as an indicator of climatic variations? Clim Change 2:127-138

Carter TR (1998) Changes in the thermal growing season in Nordic countries during the past century and prospects for the future. Agricult Food Sci Finland 7(2):161-179

Carter TR, Posch M, Tuomenvirta H (1996) The SILMU scenarios: specifying Finland's future climate for use in impact assessment. Geophysica 32(1-2):235-260

Chmielewski FM, Rötzer T (2002) Annual and spatial variability of the beginning of growing season in Europe in relation to air temperature changes. Clim Res 19:257-264

Cubasch U, Meehl GA, Boer GJ, Stouffer RJ and 37 others (2001) Projections of future climate change. In: Houghton JT, Ding Y, Griggs DJ, Noguer M, van der Linden PJ, Dai X, Maskell K, Johnson CA (eds) Climate change 2001: the scientific basis. Contribution of Working Group I to the Third Assessment Report of the International Panel on Climate Change. Cambridge University Press, Cambridge, p 525-582

Davis JC (1973) Statistical and data analysis in geology. John Wiley \& Sons, New York, p 239-248, 383-405

Førland EJ, Roald L, Tveito OE, Hanssen-Bauer I (2000) Past and future variations in climate and runoff in Norway. DNMI Report 19/00 Klima, Norwegian Meteorological Institute, Oslo

Groisman PYa, Sun B, Vose RS, Lawrimore JH and 6 others (2003) Contemporary climate changes in high latitudes of the Northern Hemisphere: daily time resolution. In: WMO Proceedings of the International Symposium on Climate Change, Beijing, China, 31 March-3 April, 2003. WMO/ TD-1172, World Meteorolical Organisation, Geneva, p 51-55
Hanssen-Bauer I, Nordli PØ (1998) Annual and seasonal temperature variations in Norway 1876-1997. DNMI Report 25/98 Klima, Norwegian Meteorological Institute, Oslo

Hanssen-Bauer I, Tveito OE, Førland EJ (2000) Temperature scenarios for Norway: empirical downscaling from the ECHAM4/OPYC3 GSDIO integration. DNMI Report 24/00 Klima, Norwegian Meteorological Institute, Oslo

Hanssen-Bauer I, Førland EJ, Haugen JE, Tveito OE (2003) Temperature and precipitation scenarios for Norway: comparison of results from dynamical and empirical downscaling. Clim Res 25:15-27

Høgda KA, Karlsen SR, Solheim I (2001) Climatic change impact on growing season in Fennoscandia studied by a time series of NOAA AVHRR NDVI data. In: Geoscience and Remote Sensing Symposium, 2001, Sydney, IGARSS '01. IEEE 2001 International, 3(9-13 July 2001):1338-1340

Menzel A (2002) Phenology: its importance to the global change community (Editorial comment). Clim Change 54: 379-385

Menzel A, Fabian P (1999) Growing season extended in Europe. Nature 397:659

Patterson DT, Westbrook JK, Joyce RJV, Lindgren PD, Rogasik J (1999) Weeds, insects and diseases. Clim Change 43:711-727

Press WH, Teukolsky SA, Vetterling WT, Flannery BP (1992) Numerical recipes in FORTRAN. Cambridge University Press, Cambridge

Räisänen J (2001) Intercomparison of 19 global climate change simulations from an Arctic perspective. In: Källen EV, Kattsov J, Walsh E, Weatherhead B (eds) Report from the Arctic Climate Impact Assessment Modelling and Scenario Workshop, Stockholm, Sweden, January 2001. ACIA Secretariat, Fairbanks, AK, p 11-13

Roeckner E, Bengtsson L, Feichter J, Lelieveld J, Rohede H (1999) Transient climate change simulations with a coupled atmosphere-ocean GCM including the tropospheric sulphur cycle. J Clim 12:3004-3032

Rötzer T, Chmielewski FM (2001) Phenological maps of Europe. Clim Res 18:249-257

Sparks TH, Menzel A (2002) Observed changes in seasons: an overview. Int J Climatol 22:1715-1725

Tveito OE, Førland EJ, Heino R, Hanssen-Bauer I and 7 others (2000) Nordic temperature maps. DNMI Report 09/00 Klima, Norwegian Meteorological Institute, Oslo

Tveito OE, Førland EJ, Alexandersson HA, Drebs A, Jónsson T, Tuomenvirta H, Vaarby Laursen E (2001) Nordic climate maps. DNMI Report no 06/01 Klima, Norwegian Meteorological Institute, Oslo

Venäläinen A, Nordlund A (1988) Kasvukauden ilmastotiedotten sisältö ja kÿttö. Report 1988:6, Finnish Meteorological Institute, Helsinki

Wahba G (1990) Spline models for observational data. In: CBMS-NSF Regional Conference Series in Applied Mathematics, Vol 59. Soc Ind Appl Maths, Philadelphia, PA 
Appendix A. Validation of the growing season (GS) estimates with the use of smoothed mean monthly data compared to daily temperature data

As described in Section 3.3, the GS is defined as the period of the year when the daily mean temperature is above $5^{\circ} \mathrm{C}$. Carter (1998) states, 'in any individual year the spring and autumn periods are usually characterised by frequent departures above and below the $5^{\circ} \mathrm{C}$ threshold.' This implies that setting the dates for the start and end of the GS may be nontrivial, which is illustrated in Fig. A1. Days with daily mean temperature above $5^{\circ} \mathrm{C}$ are plotted for Stns 80700 (Glomfjord) and 18700 (Oslo-Blindern) (northwestern Norway and southeastern Norway, respectively). At Stn 80700 (Glomfjord), the daily mean temperature fluctuates around $5^{\circ} \mathrm{C}$ several days a year. The definition of the GS is therefore sometimes ambiguous. In Oslo, the definition is accurate in most cases, but still there are years when the definition gives ambiguous results. Thus, certain rules for smoothing of the mean daily temperature are commonly applied. The start of the GS (when for at least $5 \mathrm{~d}$ the long transient mean temperature is above $5^{\circ} \mathrm{C}$ ) and the end of the GS (the day when the $10 \mathrm{~d}$ mean temperature falls below $5^{\circ} \mathrm{C}$ ) are plotted as well.

In this paper, the length of the GS was calculated from smoothed monthly mean temperature. In order to evaluate this method, the results at 4 sites were compared with calculations based on the daily method. A smoothing of the daily data was applied to avoid the influence of day-to-day variability around $5^{\circ} \mathrm{C}$ (Venäläinen \& Nordlund 1988). The 4 stations are located in the southeast (Stn 18700), southwest
(Stn 46610), northern (Stn 80700) and 'northernmost' (Stn 93900) parts of the country (Fig. 1). Both the GS and the GDD within the GS were compared (Table A1). The mean length of GS for the $20 \mathrm{yr}$ period is quite similar. The monthly values lead to a GS a few days longer compared to the daily method. However, the GDD is larger (2 to $6 \%$ ) when calculated with the daily method. This is because the mean monthly temperature is based on all temperature observations, while the daily method does not include days with daily mean values below $5^{\circ} \mathrm{C}$. The year-to-year variability in the GS and GDD is also reproduced well by the monthly method (Fig. A2).

Table A1. Estimated length of growing season (GS) and growing degree-days (GDD) based on 'daily' and smoothed ('monthly') temperature

\begin{tabular}{|c|c|c|c|c|}
\hline \multirow[t]{2}{*}{ Stn } & \multicolumn{2}{|c|}{$\begin{array}{l}\text { Change in } \\
\text { length of GS }\end{array}$} & \multicolumn{2}{|c|}{$\begin{array}{c}\text { Change in GDD } \\
\text { within GS }\end{array}$} \\
\hline & (d) & $(\%)$ & $\left({ }^{\circ} \mathrm{C}\right)$ & $(\%)$ \\
\hline 18700 & 4 & 2.2 & -30 & -2.1 \\
\hline 46610 & 0 & 0 & -33 & -2.5 \\
\hline 80700 & 7 & 4.2 & -22 & -2.5 \\
\hline 93900 & 7 & 6 & -30 & -5.8 \\
\hline
\end{tabular}

a

Stn 80700 Glomfjord

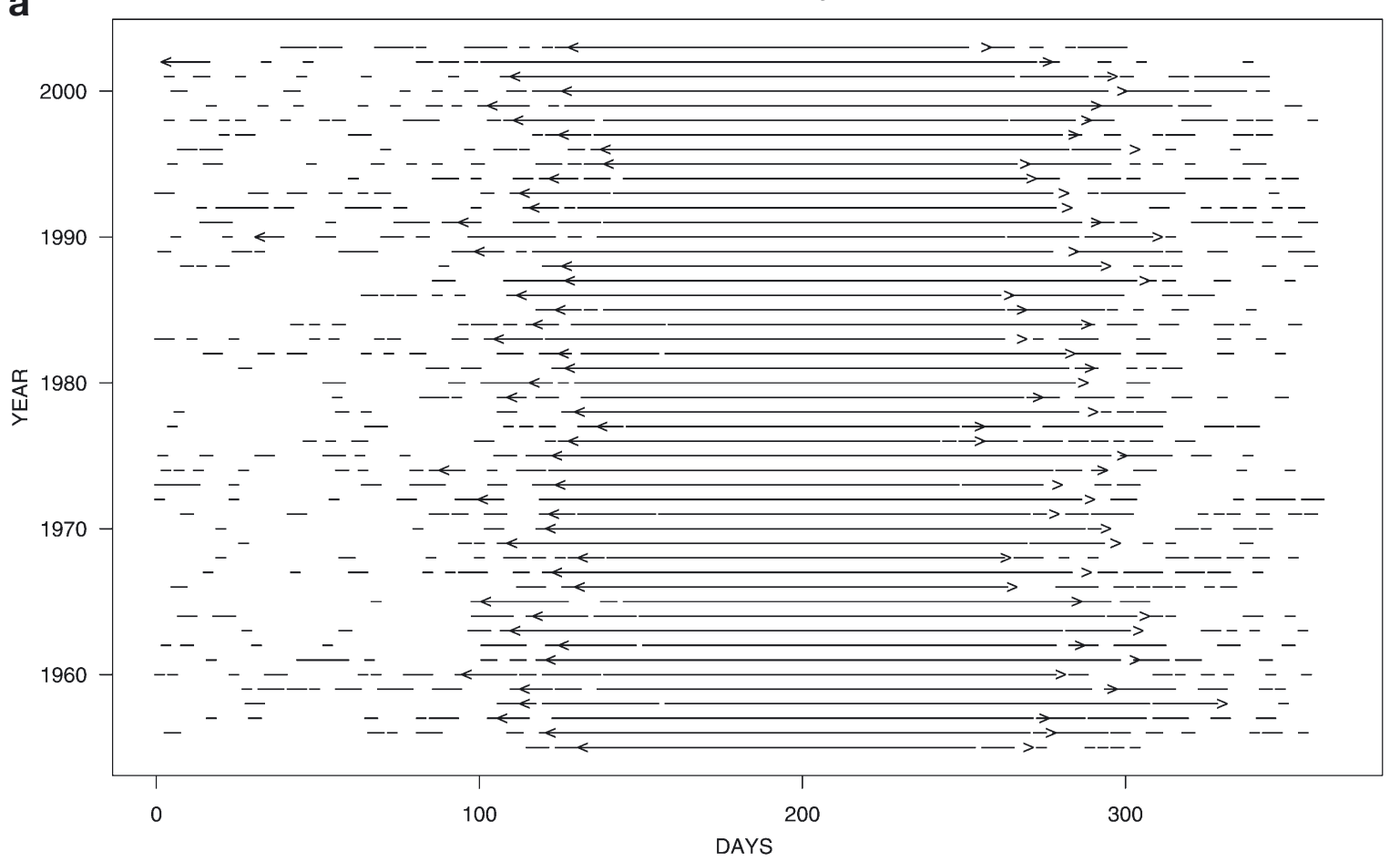

Fig. A1. (Above and facing page.) Days with daily mean temperature above $5^{\circ} \mathrm{C}$ at (a) Stn 80700 (Glomfjord) (1956-2003) and (b) Stn 18700 (Oslo-Blindern) (1956-2003) 
Appendix A (continued)

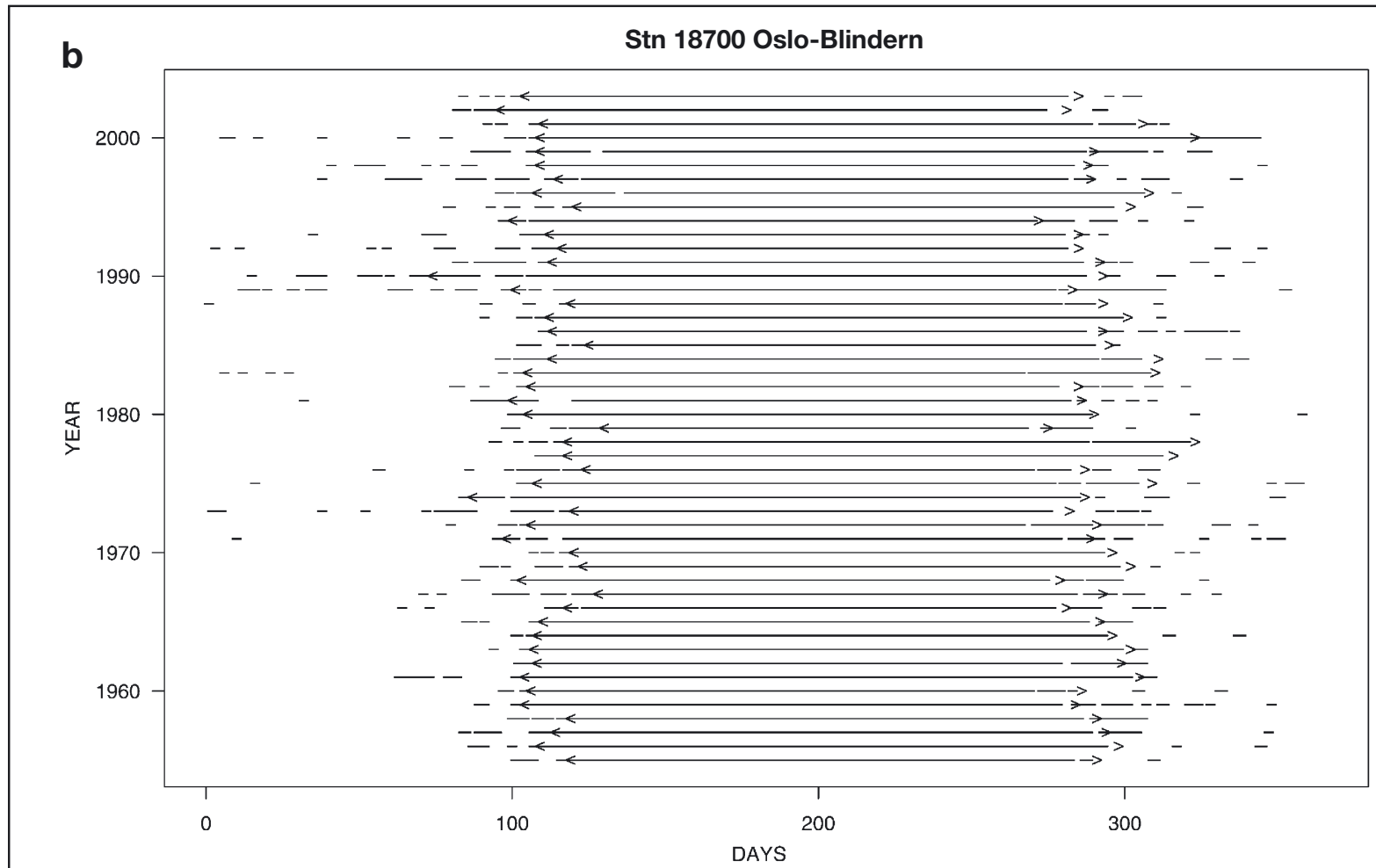

Fig. A1 (continued)

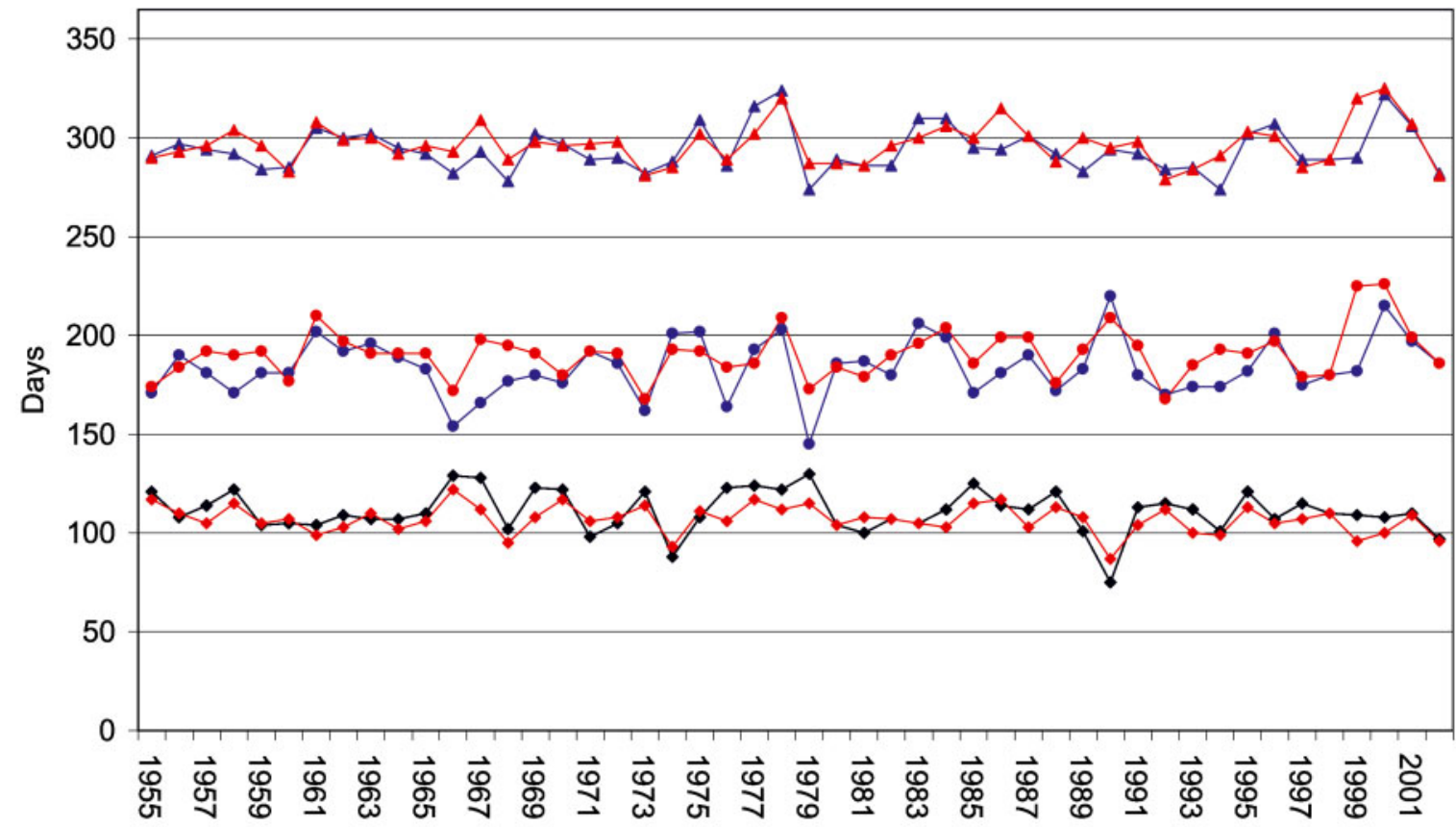

\section{END-daily $\leadsto$ - GDD-daily $\rightarrow-$ START-daily $\rightarrow$ END-monthly $\rightarrow-$ START-monthly $\rightarrow-$ Length-monthly}

Fig. A2. Year-to-year estimate of the start and end of the GS and GDD at Stn 18700 (Oslo-Blindern) for 1955-2003 
Appendix B. Evaluation of the spatial interpolation technique

A cross-validation of the spatial interpolation of monthly temperature anomalies was performed for 1981-2000. The monthly temperature anomalies are defined as the difference between the mean monthly temperature at 134 stations in Norway and the 1961-1990 standard normal temperature for that particular month. The variability in the temperature anomalies studied is larger in winter months than in summer months (Fig. B1), indicating that the regional temperature distribution is more complex during winter than summer.

The results of the cross-validation are presented in Fig. B2. With a perfect model, all values should be equal to 0 . However, as shown in the figure, this is not the case. To evaluate the cross-validation results, the following criteria are given:

- The mean $(m)$ and median $(M)$ of the anomalies value should be equal to 0 .

- The number of values estimated outside of the $95 \%$ confi- dence interval $(B)$ should not exceed $5 \%$ of total number of observations ( $B<=7$ in this case).

- The results are presented in Table B1.

- The first criterion is fulfilled for all months. The second criterion is not fulfilled for the months February-April and September-December. This is partly caused by 'outliers'. However, the locations of the 'outliers' differ from month to month. Since only $20 \mathrm{yr}$ of data were available for this evaluation, this criterion might be too strict-outliers are given relatively high weight. With a $90 \%$ confidence interval, 13 observations are allowed outside the confidence interval $(B=13)$. The second criterion would then be fulfilled for all months.

The interpolation method is thus found to be acceptable, especially in the months from March until September/October, which are the most important months concerning GS. This is reflected in Fig. B1, which indicates larger standard deviation in winter than during summer.

Table B1. Values of the criteria used to evaluate the cross-validation of the spatial interpolation method. ( $m$ is the mean value, $M$ the median value, SE is the standard deviation and $B$ is the number of values estimated outside of the $95 \%$ confidence interval)

\begin{tabular}{|lcccccccccccc}
\hline & Jan & Feb & Mar & Apr & May & Jun & Jul & Aug & Sep & Oct & Nov & Dec \\
\hline$m=0$ & 0.0 & 0.0 & 0.0 & 0.0 & 0.0 & 0.0 & 0.0 & 0.0 & 0.0 & 0.0 & 0.0 & 0.0 \\
$M=0$ & 0.0 & 0.0 & 0.0 & 0.0 & 0.0 & 0.0 & 0.0 & 0.0 & 0.0 & 0.0 & 0.0 \\
SE & 0.326 & 0.334 & 0.206 & 0.164 & 0.194 & 0.216 & 0.172 & 0.196 & 0.227 & 0.212 & 0.260 & 0.285 \\
$B<=7$ & 6 & 10 & 5 & 5 & 9 & 4 & 1 & 9 & 8 & 7 & 7 \\
\hline
\end{tabular}

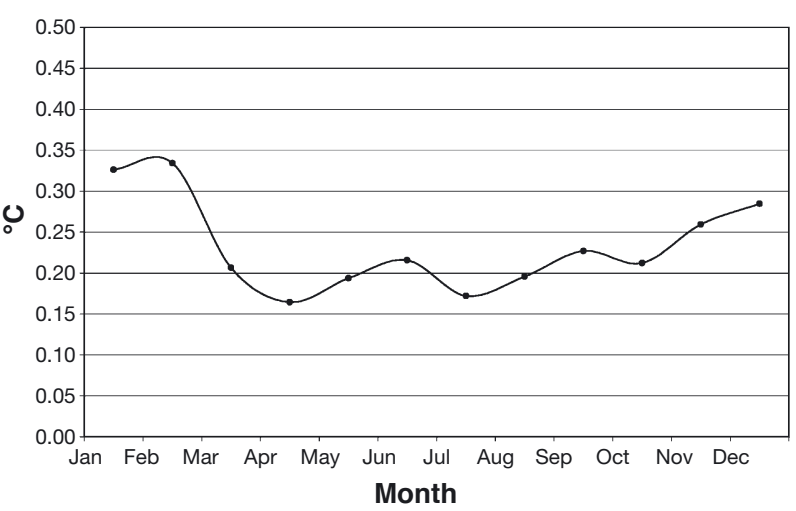

Fig. B1. Standard deviation of the temperature anomalies between the mean monthly temperature value in normal period 1961-1990 and the $20 \mathrm{yr}$ period 1981-2000 at each station used

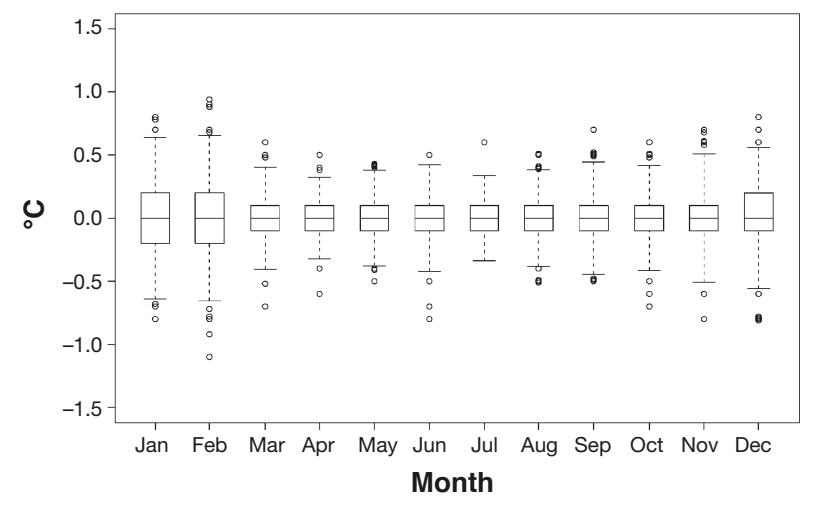

Fig. B2. Box plot of the error distribution obtained with cross-validation $\left({ }^{\circ} \mathrm{C}\right)$ between observed and estimated mean monthly temperature anomalies at 134 stations. (The median, first and third quartile values are shown)
Editorial responsibility: Hans von Storch, Geesthacht, Germany
Submitted: June 7, 2003; Accepted: April 29, 2004

Proofs received from author(s): June 7, 2004 